\title{
Limites do discurso identitário na disputa eleitoral
}

\section{The limits of identitarian discourses in electoral campaigns}

\author{
Ercio Sena ${ }^{1}$
}




\section{Resumo}

Com o esvaziamento da luta pelo socialismo e a ascensão do neoliberalismo, o campo da esquerda progressista tem sido criticado por tomar a questão identitária como principal motor das lutas sociais. A proposta deste trabalho é identificar e analisar o debate sobre as lutas por reconhecimento identitário na campanha eleitoral de 2018. Serão consideradas as polarizações sobre o tema entre os dois partidos localizados à esquerda do espectro político - PT e PSOL - em relação à campanha majoritária do campo localizado à direita, representada pelo PSL. A partir de suas posições em relação ao tema, explicitadas em uma rede social, pretende-se observar e problematizar os limites desses embates discursivos.

Palavras-chave

Reconhecimento, identidade, representação.

\section{Abstract}

With the rise of neoliberalism and the deflation of socialist perspective, the left-wing field has been criticized for taking the identity issue as its main engine for social struggles. This article aims to analyze this identitarian debate in the 2018 electoral campaign in Brazil. The polarization on the issue in the discourses of two left-wing parties will be considered - Partido dos Trabalhadores (PT) and Partido Socialismo e Liberdade (PSOL) in relation to the discourses of the conservative party Partido Social Liberal (PSL). The intention is to observe those positions in a social network, noticing and problematizing the limits of the struggles for identity and recognition that guides the political debate.

\section{Keywords}

Recognition, identity, representation. 
Na última campanha presidencial, as redes sociais foram mobilizadas como arena de disputas, povoadas por discursos que envolveram os candidatos à presidência da república. Neste processo, a mais exitosa força do pensamento neoliberal foi representada pela candidatura de Jair Bolsonaro, do Partido Social Liberal (PSL), esteio das teses centrais defendidas pela "nova" direita que assumiu o poder político no Brasil. As forças de esquerda, por sua vez, buscaram enfrentar o embate com o candidato favorito nas eleições pelo viés das bandeiras identitárias e da defesa das minorias socialmente representadas, como notado na estratégia empreendida nas redes sociais, especialmente no Instagram. Neste trabalho, busca-se reiterar os limites da identidade como bandeira central no enfrentamento ao discurso neoliberal.

Os partidos de esquerda, analisados em sua estratégia no uso do Instagram, foram o Partido dos Trabalhadores (PT) e o Partido Socialismo e Liberdade $(P S O L)^{2}$ que, em confronto direto com a candidatura do PSL, optaram pela defesa e valorização de identidades socialmente subjugadas, alvos comuns do discurso bolsonarista mesmo antes das eleições. Apoiados num discurso que valorizava a busca do reconhecimento de parcelas espoliadas da população, a campanha do PT se somou ao discurso predominante do PSOL para trazer, na rede social em questão, denúncias e demandas destes setores no enfrentamento com a candidatura de Bolsonaro, quando esta se consolidou na liderança da disputa eleitoral.

Nas lutas identitárias, os conflitos impulsionam a busca da universalidade do direito ou da valorização das diferenças entre diferentes grupos para se estabelecer o reconhecimento (HONNETH, 2017). Identidade e reconhecimento, portanto, fazem parte de um mesmo fenômeno3; porém, o primeiro conceito é condição para o estabelecimento do segundo. A busca do reconhecimento, 
para Axel Honneth (2017), opera-se a partir do desrespeito que ocorre na recusa de direitos ou mesmo na privação de recognição a que grupos ou pessoas estão sujeitas. Quando essa recusa ocorre, tenta-se transformar a negatividade de denegação do reconhecimento no reencontro das distinções e valorações que o torne positivo. Ou seja, de uma experiência de rejeição, passa-se para uma prática conflituosa que busca a afirmação e reconhecimento dos grupos prejudicados.

Quando formas de reconhecimento são recusadas, emerge uma crise moral que só será superada com procedimentos comunicacionais, por meio dos quais o conflito será expresso para restabelecer o respeito do indivíduo ou grupo prejudicado em suas normas de convivência. Para que o desrespeito estimule a resistência é necessário que algumas condições sejam dadas e um movimento de reparação das injustiças se estabeleça. Na maior parte dessas condições, é possível destacar a importância dos processos de significação, construídos em práticas comunicacionais não valorizadas devidamente no arcabouço teórico delineado por Honneth. Como forma de salientar a importância das trocas simbólicas na constituição desses conflitos, enumeramos, dentre as condições destacadas por Honneth, aquelas que só podem se realizar considerando a centralidade dos processos comunicacionais.

Inicialmente, destaca-se a semântica coletiva, fundamental para que os movimentos erijam suas estratégias e ações a partir de um nivelamento de compreensão sobre práticas e experiências a serem traduzidas e publicizadas na linguagem. Na formação de um quadro reflexivo de experiências morais, uma segunda condição se apresenta, trazendo a importância dos processos de interação nos quais as medidas de infração das expectativas de reconhecimento foram construídas e arraigadas porque se encontram partilhadas socialmente. Como terceira condição associada aos processos comunicacionais, aponta-se para as formas de lesão coletiva, na medida em que esses danos devem ser articulados num quadro interpretativo para que sejam reconhecidos por uma coletividade inteiramente atingida. A formação de movimentos sociais traz uma quarta condição, por meio da qual se retoma a importância da semântica coletiva e 
mesmo do quadro interpretativo, no qual o desapontamento pessoal é partilhado, impelindo a ação orgânica de uma coletividade. E, por fim, aponta-se para o enriquecimento das representações, processo constante de valorização das práticas e narrativas constitutivas de uma coletividade em busca do desenvolvimento normativo de suas práticas na vida social.

De acordo com este elenco de condições, é importante sublinhar, então, a importância da perspectiva comunicacional para compreender as lutas por reconhecimento, na medida em que a busca de uma partilha de significações em torno das disputas simbólicas será o esteio no qual se constituirá a gramática impulsionadora desse conflito. A representação cultural destes grupos, tomada de modo diferente de uma correspondência de verdade, mostra que há uma perspectiva ativa e constitutiva de processos sociais em interação e mutação constante. Para Stuart Hall (2016), o real se constitui também pelas representações midiáticas sobre as sociedades contemporâneas, sendo que estas primeiras não podem ser tomadas como formas cristalizadas, não passíveis de mudanças, pois estão envolvidas em processos criativos, embora acionados em um ambiente cultural em que são refletidas as questões cotidianas. Hall destaca que o sentido dado às coisas tem o poder de regular e definir contornos e condutas sobre as nossas práticas. Disso também se alimentam as lutas por reconhecimento em suas partilhas vivenciais e simbólicas e é por meio delas que as histórias e narrativas de um grupo devem estimar alguns valores em detrimento de outros, para justificar e promover as qualidades de um grupo. Sem essas práticas as sociedades não poderiam se sustentar, pois não há ação coletiva organizada sem relação com uma base de referências na qual ela se inscreve. A representação proposta por Hall conecta sentido, linguagem e cultura, buscando não somente tornar o mundo mais inteligível, mas também entender e compartilhar nele significações importantes em torno de hábitos e visões aceitas de forma generalizada. O sentido de representação aqui proposto se afasta, portanto, daquele que pretende ver o mundo refletido nela tal qual um espelho, ou mesmo daquele que escolhe 
a primazia do falante no estabelecimento do sentido desejado. O sentido de representação aqui explorado também se define no jogo das posições conflitantes e concorrentes entre si, constituindo-se com a força dos valores e referências dadas a priori, mas também pelo curso dos acontecimentos que lhe dão forma.

A partir desta perspectiva brevemente esboçada, que leva em conta a projeção de significados nas representações sociais, pretende-se problematizar dinâmicas presentes nas lutas por reconhecimento a partir dos embates discursivos localizados nos perfis do PSOL, do PT e do PSL no Instagram, no período de 3 de julho a 4 de outubro. Sem pretensão de reduzir a complexidade do jogo eleitoral aos movimentos compreendidos por meio da análise das postagens de uma rede social, assinala-se, entretanto, que este breve recorte também compõe a intrincada realidade das eleições de 2018. É evidente que ele não esgota as dinâmicas que cercam o âmbito comunicacional das campanhas, mas entende-se que dimensões dessa disputa foram representativas em expressões localizadas nas redes sociais.

\section{Identidades e reconhecimento nos partidos de esquerda}

É possível notar, a partir do estudo dos discursos veiculados no período analisado, que os partidos progressistas como o PT, mas, de modo destacado, o PSOL, priorizaram falas voltadas para as demandas por reconhecimento de grupos espoliados. No caso do segundo partido, as postagens se voltaram, prioritariamente, para a centralidade das lutas por valorização da diferença, ou seja, no combate às injustiças provocadas por desigualdades em termos culturais.

O discurso do PSOL no Instagram foi marcado, quase em sua totalidade, por abordagens ligadas às lutas antiopressão, em geral designadas por identitárias que, na maioria das vezes, desdobram-se em lutas por reconhecimento. Ao longo de todo o período analisado, essas abordagens são propostas e valorizadas, principalmente no campo cultural. Há notório predomínio de bandeiras nas quais o partido manifesta posição favorável às causas LGBT, por exemplo. 

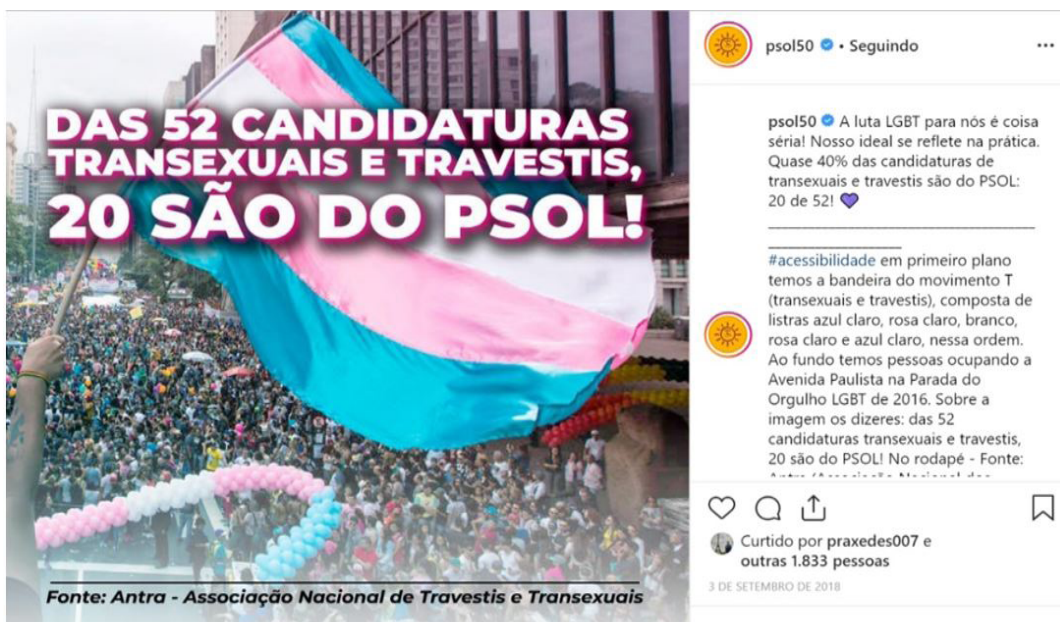

Figura 1: PSOL, o partido que mais representa as lutas identitárias

Fonte: Partido Socialismo e Liberdade (2018).

Embora seja possível identificar menções que destacam o fosso entre pobres e ricos no Brasil, este tipo de abordagem esteve longe de concorrer com os temas identitários nessa rede social. A projeção de figuras femininas, como a ex-vereadora Marielle Franco e Sônia Guajajara, candidata à vice-presidente, foi destaque entre um conjunto diverso de imagens analisadas.


Figura 2: Sônia Guajajara, candidata a vice-presidente do PSOL

Fonte: Partido Socialismo e Liberdade (2018).

Sob várias contestações e comentários contrários, ressaltam-se as postagens em favor da descriminalização do aborto, uma das principais e mais 
controversas bandeiras do movimento feminista. Nos dias que precederam e compreenderam a audiência pública proposta para discutir a ação do PSOL que trata da legalização do aborto até a $12^{a}$ semana de gestação, no Superior Tribunal Federal, as postagens foram enfáticas na defesa deste direito específico. Destacou-se, ainda, as qualidades do candidato Guilherme Boulos, enfatizando seus atributos intelectuais e compromissos com este e outros temas. No conjunto, as postagens afirmam outras manifestações em defesa de lésbicas e gays, buscando o protagonismo da luta identitária como a imagem pública mais forte do partido nessa rede social.

A estratégia de comunicação do PT no Instagram, por sua vez, apresentou três momentos distintos e articulados no mesmo período analisado. Pautas ligadas às demandas por reconhecimento não foram predominantes nas duas primeiras fases e, quando aparecem, mesclaram-se com outras questões.

No primeiro momento, o protagonismo é do ex-presidente Lula. Afirma-se a defesa de sua candidatura, sua liderança em todas as pesquisas divulgadas e o legado de seu governo. Sua vinculação com o povo é fartamente explorada, destacando-se as conquistas sociais recentes e a luta pelo seu direito de disputar as eleições. De julho até o dia 11 de setembro, predomina esta estratégia, entremeada pela presença secundária, porém constante, do seu coordenador de campanha e posterior candidato a vice-presidente, Fernando Haddad.



Figura 3: Lula candidato e sua vinculação com o povo Fonte: Partido dos Trabalhadores (2018). 
O adversário do projeto petista nas postagens desse período é o então presidente Michel Temer. Embora pouco presente, é sempre associado ao golpe sofrido pela presidente Dilma Rousseff e responsabilizado pelos problemas que afligem a maioria da população, como o aumento de preços do gás, a desarticulação dos programas sociais, o congelamento dos investimentos nessa área e as reformas (trabalhista e previdenciária) que retiram direitos etc.

No dia 13 de julho, um manifesto de mulheres em favor da candidatura Lula é articulado e divulgado na rede social. Entre outras formas de solidariedade e apoio, o documento se posiciona favorável à liberdade e ao direito do expresidente disputar a eleição. As inserções que tratam da questão racial, por sua vez, estão sempre articuladas à discussão sobre as oportunidades geradas para esses grupos no período do governo Lula. Nesse processo, o dia da visibilidade lésbica e bissexual é pontualmente lembrado por uma postagem isolada do contexto marcado pela presença do ex-presidente, suas realizações e a importante colaboração de Haddad durante os oito anos do governo Lula. Aos poucos, as postagens que privilegiam a candidatura Lula vão introduzindo mais frequentemente o nome do candidato a vice, buscando a imbricação e a fusão de suas ações na percepção do eleitor.
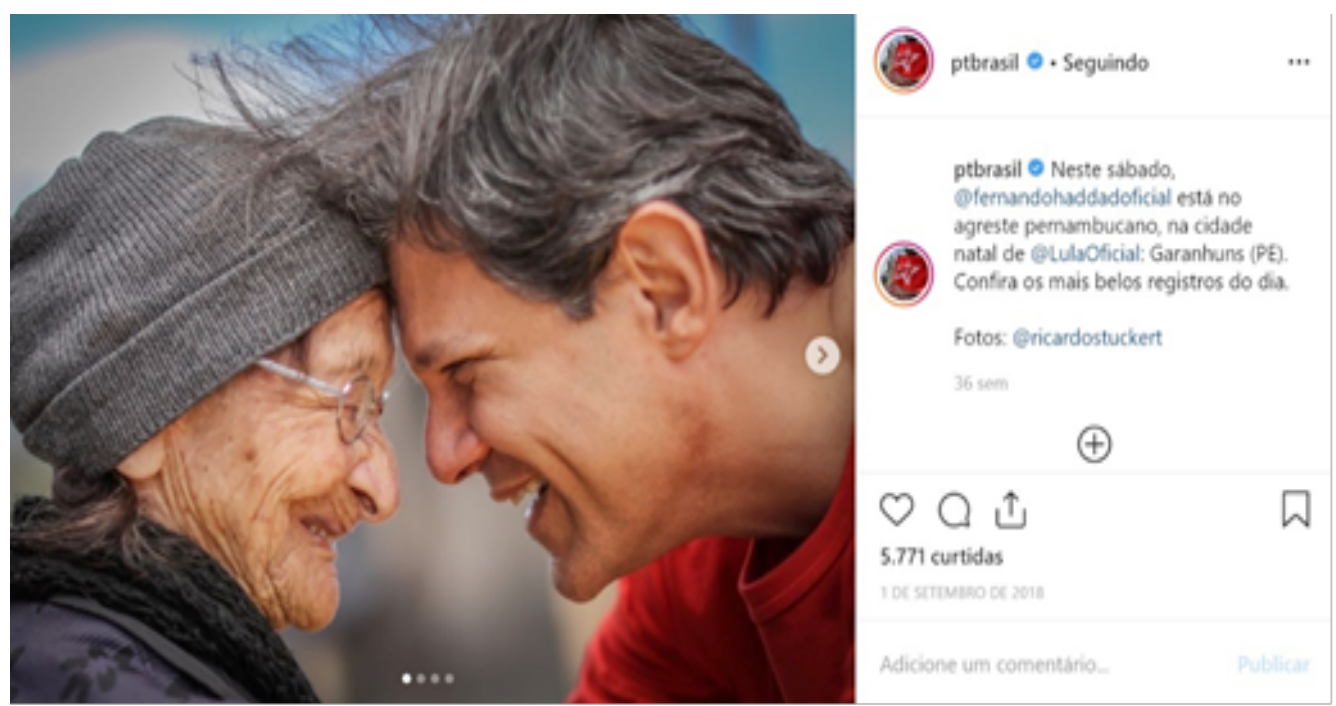

Figura 4: Haddad, o herdeiro de Lula

Fonte: Partido dos Trabalhadores (2018). 
A partir do dia 11 de setembro, a estratégia do partido no Instagram reflete, num segundo momento das postagens, a mudança oficial para a candidatura Haddad. Com diminuição da imagem do ex-presidente, instaura-se um novo protagonismo, promovendo-se, definitivamente, imagens do novo candidato. A presença da imagem do ex-presidente Lula seguirá de forma discreta, embora a assinatura da chapa concorrente seja "Haddad é Lula", sempre no mesmo tamanho de letra, tendo logo abaixo, em menor proporção, o nome da candidata à vice-presidência, Manuela D'Ávila, do Partido Comunista do Brasil (PCdoB). O trabalho segue no reforço da memória do governo Lula, buscando o retorno da autoestima dos brasileiros e das conquistas sociais dos governos do PT. Nesta transição, a imagem do candidato Fernando Haddad será intensamente associada ao legado do ex-presidente, buscando possíveis articulações entre os dois na igualdade dos propósitos, com o objetivo de produzir uma nova personificação do projeto representado por Lula, a maior liderança do partido.

Embora o que predominará nas inserções será o legado de Lula, um terceiro momento se distingue a partir do dia 16 de setembro, com a candidata Manuela assumindo um novo protagonismo na defesa da participação das mulheres no futuro governo, retomando a discussão em termos identitários, com foco na questão de gênero. Observa-se que, a partir daí, passa-se a uma postura de enfrentamento com a campanha que lidera as pesquisas; porém, há uma escolha para que esse confronto não se dê diretamente com candidato do PSL. Notado por suas declarações de cunho machista, o PT opta, no Instagram, por explorar mais a imagem da candidata à vice em contraposição às declarações de Bolsonaro, repercutidas na imprensa e nas mídias sociais. Estas aparições são vinculadas aos projetos dos governos Lula, mostrando a valorização das mulheres e de suas lutas contra a violência e a desigualdade. Pretendeu-se, com isso, indicar a importância que elas tiveram nas gestões do PT e o papel importante que terão no futuro governo. Secundariamente, Ana Estela Haddad, esposa do candidato à presidência, aparece como figura de destaque no contexto da campanha. Apresentada prioritariamente como 
professora, ela assumirá também a condição de esposa do petista, estratégia que buscou afirmar a importância da família no contexto da campanha.


Figura 5: O protagonismo da mulher no futuro governo Haddad

Fonte: Partido dos Trabalhadores (2018).

Nas estratégias empreendidas pelo Partido dos Trabalhadores no Instagram, evidencia-se a escolha por adiar o enfretamento aberto com o candidato favorito para outro momento da campanha. Embora sua liderança estivesse consolidada, nenhuma menção direta foi feita a ele, ao contrário do que ocorreu com o então presidente, Michel Temer. A opção foi articular o contraponto de suas ideias por meio da valorização da candidatura feminina na composição da chapa presidencial com relevo para as realizações do governo Lula no reconhecimento dos grupos desprivilegiados.

\section{Os limites do reconhecimento e as apropriações neoliberais}

A questão da identidade, embora fundamental, foi, conforme Safatle (2017), transformada na única pauta política concreta da esquerda, que se viu impossibilitada de lutar por uma transformação radical da sociedade. Como foi possível notar, o enfoque nas políticas identitárias percorreu parte substancial do discurso dos partidos de esquerda durante a campanha eleitoral, momento significativo para perceber as prioridades dos embates políticos. 
Ao superestimar dimensões morais e culturais nas lutas de classes, as demandas por reconhecimento se constituíram, no entendimento de Safatle $(2015,2017)$, no vácuo deixado pelo esvaziamento do proletariado. Diferentemente de outras gerações, que estiveram atentas ao ideal socialista e lutaram por transformações radicais na estrutura política e econômica, os atores políticos comprometidos com as lutas por reconhecimento, em termos identitários trabalhados por Honneth, voltam-se contra hierarquias culturais que condicionam determinados grupos historicamente vulneráveis, como negros, mulheres, gays etc. O engajamento derivado dessas lutas se dá em direção a múltiplas particularidades, desafiando fundamentalmente a hegemonia cultural de determinados grupos sociais.

A luta culturalista e identitária por reconhecimento, reforçada teoricamente por Honneth, é tensionada, também, no pensamento da filósofa Nancy Fraser (2006), que a considerada limitada. Ela discute a importância de se considerar duas diferentes dimensões das lutas por emancipação, acrescentando à teoria do reconhecimento a discussão sobre a redistribuição. Fraser destaca o contraste entre a afirmação das diferenças, presentes nas demandas identitárias, e a abolição delas, defendida no campo da redistribuição, e propõe "remédios" afirmativos e transformativos nos dois âmbitos. No campo da distribuição, não trabalhada de modo efetivo pelo filósofo alemão, ela reforça, especificamente, a importância de remédios afirmativos que corrijam os efeitos da injustiça distributiva - políticas que se encontram irmanadas, por exemplo, na defesa da seguridade do Estado de bem estar social -, assim como dos remédios transformativos, que estariam no horizonte das lutas por alterações mais profundas das estruturas geradoras de desigualdade e injustiça, como a luta pelo socialismo. Assim como Safatle, Fraser entende que, no apagamento das desigualdades distributivas e no refluxo das lutas socialistas, essas formas de insurgência foram subordinadas teórica e politicamente aos embates pela ressignificação cultural. Esse desprendimento facilitou a insurgência do neoliberalismo como racionalidade hegemônica, cujo objetivo era reprimir, a qualquer custo, a perspectiva de um igualitarismo social. 
O neoliberalismo, para Pierre Dardot e Christian Laval (2016), não é apenas uma nova fase do capitalismo tal qual esse sistema foi desde suas origens. Longe de ser uma ideologia ou uma política econômica expressa nela, os autores o definem como um sistema pós-democrático, capaz de criar uma nova normatividade que amplia sua influência no mundo, transformando profundamente o capitalismo. A gênese e o entendimento do neoliberalismo ultrapassariam a tentativa de identificálo em práticas em que há ou não regulação estatal na economia, tomando-se o anti-intervencionismo como princípio. Neste sentido, são destacadas a sua capacidade de autofortalecimento, seu vigor e predomínio em todos os domínios das relações humanas. No neoliberalismo, a ação coletiva se tornou ainda mais complexa, uma vez que a concorrência, e não a solidariedade entre os indivíduos, é estimulada em todos os níveis da vida social. Neste cenário, as possibilidades de enfrentamento ao neoliberalismo são constantemente minadas em várias frentes de desestímulo à participação política e qualquer tipo de mobilização coletiva. Há um inegável enfraquecimento das formas de reação ao neoliberalismo, um sistema normativo mais abrangente, capaz de orientar não somente os governos, as empresas, mas também milhões de pessoas no planeta que agem de acordo com esta racionalidade, mesmo sem ter, necessariamente, consciência disso.

A capacidade de atuar como uma nova racionalidade leva o neoliberalismo a orientar a produção de um modo de existência adequado para nortear relações sociais e formas de viver, tornando-se referência para a constituição de subjetividades marcadas por uma competição generalizada, segundo os modelos de funcionamento do mercado. Esse modelo é responsável por estruturar e organizar a conduta dos indivíduos no mundo, na medida em que essas formas justificam as assimetrias e as injustiças, retirando do sistema qualquer culpabilidade, responsabilizando unicamente o indivíduo, tratado como empresa.

Cabe mencionar, ainda, o fenômeno da desdemocratização, processo pelo qual os autores franceses demonstram não a sua extinção, mas seu constante esvaziamento. Para que o ordenamento racional da empresa se afirme em todos os domínios, é fundamental enfraquecer as instituições, abrindo livre curso para 
os interesses empresariais apresentados como interesse de todos. A resiliência do neoliberalismo ultrapassa a lógica do mercado, indo além dele. Conforme Dardot e Laval (2016), essa lógica produz uma subjetividade contábil que acaba por se tornar um modo de vida, fazendo com que não haja apenas um modelo econômico a ser enfrentado, porém um quadro normativo a ser desmantelado e substituído por outra razão.

Por este conjunto de características apontadas no contexto do neoliberalismo, é importante afirmar que as lutas que não se propunham a enfrentar transformativamente, não somente o sistema econômico, mas também essa nova racionalidade, terá alcance limitado. Se esta é uma realidade global que orienta modos de vida e valores nas práticas cotidianas, elas devem ser enfrentadas nas lutas identitárias, mas também além delas. Retomando-se as ideias advogadas por Safatle (2015), o sujeito neoliberal tem sua consciência articulada por meio de posse de atributos, predicados, narrativas ou objetos. O autor entende que o fracionamento das demandas de grupos ou indivíduos leva à criação de nichos culturais que desembocam em demandas e predicados em busca de audiência e legitimidade como forças concorrentes. Embora as determinações gerais provenientes da ordem neoliberal permeiem o conjunto das relações sociais, elas seguem sendo enfrentadas isoladamente, nem sempre no sentido de seu enfraquecimento.

É precisamente desta formulação identitária, esvaziada de seus propósitos emancipatórios, que o discurso do PSL, personificado na figura de Jair Bolsonaro, irá se apropriar, contrapondo-se, assim, às acusações mobilizadas por seus adversários. O candidato de declarações machistas, sexistas, racistas e LGBTfóbicas usou a aproximação com indivíduos representantes desses grupos a seu favor.

\section{A representatividade deglutida no discurso do PSL}

Considerando as postagens a partir do dia 3 de junho, quando o PSL inicia sua atuação no Instagram, podemos demarcar, em delineamentos bem gerais, três fases diferentes, porém interligadas, do discurso eleitoral conduzido por 
este partido. Abusando das cores da bandeira brasileira, a candidatura tentou se identificar com os movimentos críticos dos governos petistas, buscando associação com seus valores e símbolos e retomando a estética dos discursos que levaram ao impeachment da presidente Dilma.

No primeiro momento, o partido afirma o discurso anticorrupção, criticando as relações políticas entre o Congresso e o Executivo. O candidato se coloca como avalista de um novo padrão de relacionamento a ser inaugurado em seu governo. A referência negativa da relação com o Congresso estará sempre associada às últimas gestões do Partido dos Trabalhadores, desconsiderando-se o período do Governo Temer, empenhado também em reformas que reduziram direitos e obrigações sociais do Estado.
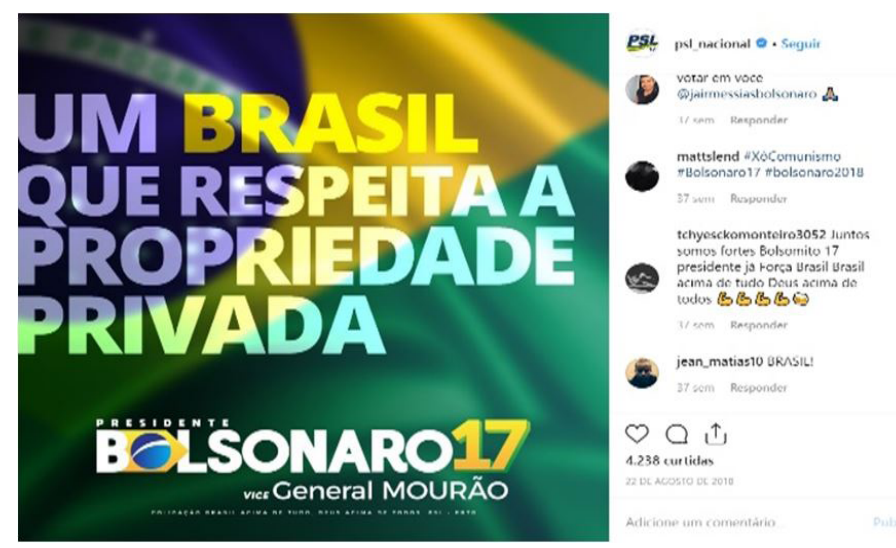

Figura 6: A defesa da propriedade

Fonte: Partido Social Liberal (2018).

A defesa da propriedade privada como bandeira de governo sugere outro padrão de relação com os movimentos sociais, em particular o Movimento dos Trabalhadores Sem Terra (MST) e o Movimento dos Trabalhadores Sem Teto (MTST). A demarcação dessas posições é ancorada em diversos ataques que o candidato faz a esses movimentos, considerados em aspectos morais pela violação da ordem e do direito da população. O conflito com essas posições é anunciado como compromisso do governo que se pretende inaugurar com a eleição do candidato militar. Essa prática se associa a outras na qual fica implícita 
a disposição de reduzir os espaços de manifestação e luta pela propriedade da terra e pelo direito à moradia. A bandeira do candidato contribui com o propósito de reduzir os espaços democráticos e de conflitos sociais tomados, até então, como legítimos na sociedade brasileira. Nota-se que a posição afirmada aponta para uma redução, ainda maior, da intensidade da democracia brasileira com a disposição não só de restringir direitos, mas de enfraquecer o poder de resistência dos grupos vítimas da desigualdade econômica e da injustiça social.

Além de bandeiras como essas, a campanha destacou outros tópicos de um programa marcado por valores neoliberais, focado na eficiência gerencial. Há ainda manifestações fortemente anti-institucionais, como a defesa do armamento individual para se coibir a violência. Como resposta à insegurança dos eleitores, ocorre o incentivo para que eles tomem para si a defesa de seus interesses e de sua própria vida, advogando-se o "direito" de armamento da população civil.

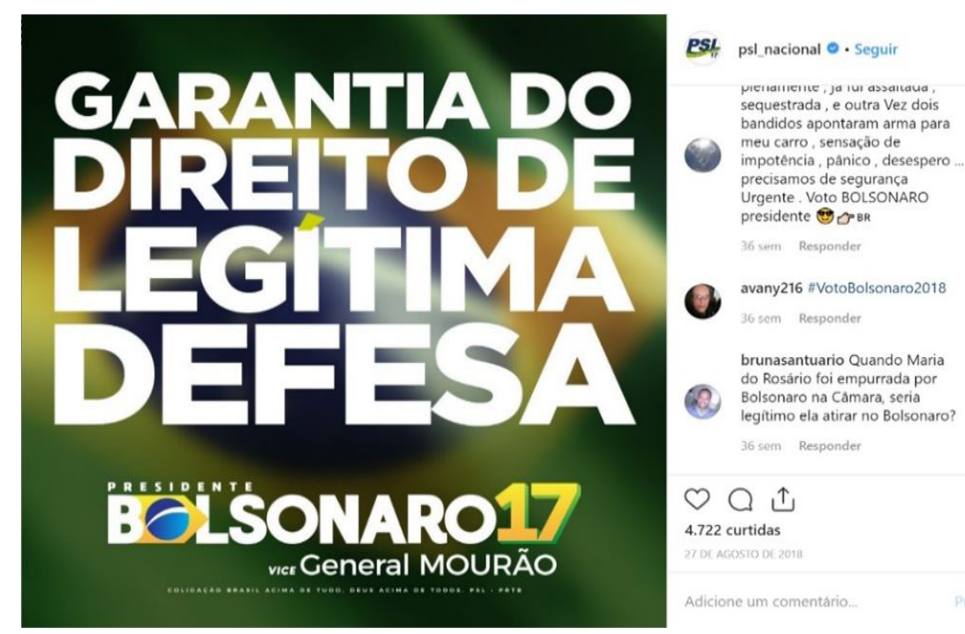

Figura 7: O direito de armamento da população Fonte: Partido Social Liberal (2018).

Esta perspectiva acentua outro aspecto que se tornou símbolo da campanha, que é o incentivo à violência a partir do porte de arma do chamado "cidadão de bem". A garantia da legítima defesa, já explicitada na Constituição, torna-se uma ação ofensiva, incentivando-se o uso da violência contra os mais frágeis. O monopólio da violência pelo Estado, conquista das sociedades modernas, é abordado numa 
perspectiva ultrarreacionária, retrocedendo-se a um período de ausência desta regulação em favor dos poderes privados. Nas práticas reacionárias se expressa 0 desejo de retorno a um passado que se supõe ser melhor que o presente. Isso reforça demarcações retrógadas, empenhadas em um projeto reacionário e antissecular de assegurar o recuo aos valores tradicionais de uma família ideal que se vê ameaçada.

A partir do dia 6 de setembro, data em que ocorre o episódio conhecido como a facada no candidato Bolsonaro, na cidade de Juiz de Fora, inaugura-se outra fase nas postagens do PSL. A partir desse momento, opta-se por trabalhar a solidariedade em torno do candidato, produzindo sua imagem como vítima dos adversários de suas propostas. Na postagem abaixo, além de reproduzir a estética da anterior, a promessa de vigor e força são animadas mediante o farto noticiário que apontava para debilidade e riscos que o candidato corria em função da alentada agressão.

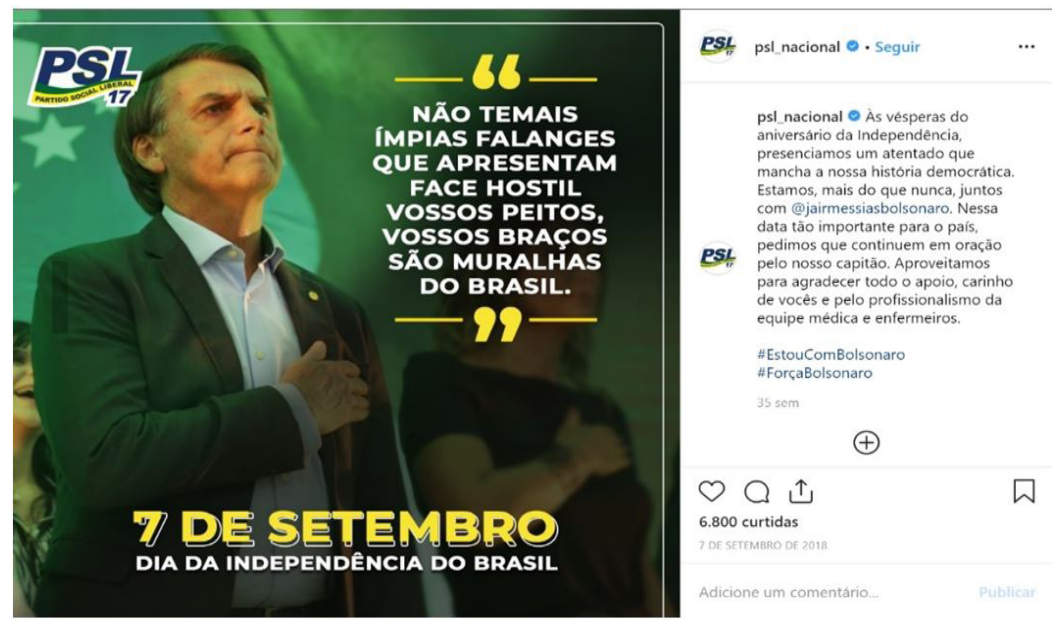

Figura 8: A facada contra Bolsonaro e o patriotismo Fonte: Partido Social Liberal (2018).

Como se observou inicialmente, a irrupção de uma nova fase não significa abandono das demarcações anteriores, entretanto, inaugurou-se outro componente no qual se destaca a narrativa de um heroísmo produzido em função da força, da coragem e da defesa de um projeto de mudanças para o país.

O terceiro momento da campanha do candidato, objeto de nossa análise, será representado pela ação responsiva às investidas de seus adversários, buscando se 
defender dos movimentos e discursos que identificam o candidato como machista, homofóbico e racista. É nesse terceiro momento, verificado a partir do dia 14 de setembro, que o candidato agirá defensivamente em relação ao discurso operado por seus adversários, o que resultou em um grande movimento de manifestações populares lideradas por mulheres: Ele não.

A partir do objeto escolhido, retomaremos três inserções nas quais o PSL reage às acusações de maior repercussão e a campanha do candidato se vê impelida a responder. Todas elas trazem a reelaboração de sua posição em relação às lutas identitárias. Bolsonaro recua de suas próprias afirmações e admite total convivência com sujeitos identificados com esses grupos, trazendo para a arena da luta política sua proximidade com eles. As postagens exibem o apoio de indivíduos pertencentes às minorias, identificando-os com a causa que o candidato representa. Com este gesto, as demandas neoliberais de seu programa seguem intocadas e não se vê como problema a incorporação de sujeitos e grupos minoritários em sua campanha, desde que eles estejam empenhados nas pautas neoliberais defendidas pelo candidato. Ressalta-se, ainda, que não se pode afirmar que as respostas dadas pelo PSL anulam os efeitos dos ataques que o candidato recebeu nessa rede social. Entretanto, não foi difícil para a candidatura Bolsonaro assimilar dimensões destes modos de existência, uma vez que a expressão dessas diferenças pode contribuir com seu projeto, desde que não sejam questionados os fundamentos das assimetrias sociais e as injustiças econômicas.

Na primeira inserção audiovisual, postada no dia 14 de setembro, a peça de propaganda tem um fundo preto com uma pergunta que se projeta na tela: "Bolsonaro disse que a mulher deve ganhar menos que o homem?". O texto se amplia e depois retrocede até desaparecer e dar lugar à presença do candidato em um programa de televisão, no qual ele está respondendo à pergunta proposta inicialmente. Em sua resposta, Bolsonaro diz que "O empresário prefere o homem à mulher". A entrevistadora retoma a palavra e o indaga novamente. "O empresário. E, no caso, o senhor, qual seria a sua opinião?". Em seguida, o candidato responde: "Sem problema nenhum. É competência. Eu não vou pagar mais pro homem só 
porque é homem e menos pra você, você sendo mais competente". Todas as falas do vídeo são acompanhadas por legendas que a destacam. O vídeo se volta para o fundo preto, agora com uma nova inscrição: "\#EstouComBolsonaro".

Marcada por um discurso machista contra as mulheres, a campanha de Bolsonaro se viu na necessidade de elaborar, ainda que no âmbito das características do candidato, a defesa do mérito como antídoto às suas práticas. Optou-se por recusar a distinção negativa contra a mulher, afirmando que as escolhas do empresariado, no geral, são discriminatórias; porém, as que ele tomará serão baseadas no critério liberal da meritocracia. Apesar das manifestações do próprio candidato, a campanha não viu problema algum em fazê-lo recuar de tais posições, visto que era possível conviver com partes dessas demandas e até incorporar reivindicações que integrassem mulheres, mantendo inalterados qualquer debate sobre a desigualdade estrutural dessas relações. As questões sobre a discriminação identitária das mulheres foi assimilada de modo simplista, mas reconhecendo que, no âmbito da campanha, as demandas trazidas pela oposição não estimularam respostas que iam além de uma afirmação discriminatória em favor da meritocracia. Na medida em que havia um natural esvaziamento da temática da luta de classes e da injustiça social no confronto com o candidato, os fundamentos do neoliberalismo ficaram secundarizados no debate da rede social analisada. Sem deixar de reconhecer a importância que essas questões tiveram para articular o enfretamento com a campanha do candidato Bolsonaro nas redes sociais, elas não bastaram para modificar a escolha da maioria dos que votaram.

Na segunda inserção audiovisual analisada, o fundo preto é acionado novamente, repetindo a mesma forma estética do vídeo anterior. A pergunta nesse vídeo é outra: "Bolsonaro é homofóbico?". A seguir o vídeo mostra um auditório lotado de pessoas com um apresentador que se encontra fora de um palco que tem uma bandeira do Brasil ao fundo. Usando um microfone, ele pergunta "Ah, 0 Amin tá aí?". Depois ele percorre parte do recinto e repete, "Ele tá aí?". Caminha em direção a um homem assumidamente gay, que aparenta uns 60 anos e veste uma blusa rosa de manga comprida. "Vou te apresentar o Bolsonaro agora. Vem cá! 
Vai!!". Quando Amim concorda e se aproxima do apresentador, o auditório aplaude a cena e, do outro lado, a figura de Bolsonaro é focalizada. O apresentador diz: "Vai dar um abraço e um beijo nele". Nesse momento, a imagem fecha na figura de Bolsonaro, que se levanta e projeta seus braços em direção ao apresentador e a Amim. O apresentador retoma: "Vamos fazer a paz!". Bolsonaro caminha em direção aos dois e o apresentador instrui Amim: "Abraça e beija!". Amim apoia o rosto de Bolsonaro com uma das mãos e depois the beija em ambas as faces. O público se manifesta e aplaude o gesto de ambos. Em seguida, o candidato o carrega e segurando Amim apenas com um braço, usa a mão livre para fazer o gesto da arma, símbolo de sua campanha, para delírio do auditório. A imagem é cortada e, em seguida, há uma nova cena, desta vez, com a fala de Amim projetada. "Espera aí. Agora eu vou falar. Eu encontro com ele na praia e eu já beijei ele, eu fui muito criticado na internet. Mas eu beijo mesmo. Ele gosta dos gays, sim, só que ele não gosta daquela cartilha que inventaram". Ao final, Amim dá três beijos sucessivos no rosto do candidato e a imagem se volta para o fundo preto, mantendose ainda o som das palmas do auditório com a inscrição: "\#EstouComBolsonaro".

Agora, o candidato se aproxima de outro grupo vítima de declarações anteriores fora do contexto da campanha eleitoral. Em uma atividade de campanha, o encontro com Amim é projetado para destacar os aspectos em que a convivência com homossexuais é possível. Pelo produto audiovisual, apesar da frágil qualidade da produção e do argumento, as formações identitárias são admitidas na convivência com o candidato, que precisa afirmar um comportamento de distinção positiva. Admitida a natureza moral das demandas por reconhecimento, a campanha encontra seu caminho, fazendo ressalva apenas ao suposto estímulo educacional à homossexualidade. Depois de sustentar a falsa versão de que o Ministério da Educação havia distribuído uma cartilha que incentivava práticas homossexuais entre as crianças, inclusive em entrevista concedida à Rede Globo, a campanha buscou um modo de diminuir o impacto contra as ações declaradamente homofóbicas do seu candidato. O vídeo optou por afirmar apenas o aspecto da convivência, não avançando em nada em termos de políticas que estimulem a convivência e a valorização da diversidade. Nem mesmo o compromisso 
com a continuidade dessas políticas é assumido. Ao contrário, elas são demonizadas em práticas que nunca aconteceram, fazendo da produção um momento a mais para reforçar as notícias falsas sobre as ações do principal adversário em sua gestão no Ministério da Educação. Ainda que o vídeo tenha buscado enfrentar, de modo raso, o debate discriminatório no campo das diferenças, a campanha do PSL considerou apenas essa forma de defesa do candidato no Instagram. No momento em que a campanha Bolsonaro saiu da ofensiva nessa rede social para responder aos golpes dos seus adversários, não havia outro debate a ser feito senão aqueles trazidos pelas pautas identitárias.

Na terceira e última inserção audiovisual analisada, a mesma estética anterior se repete, mas com outro questionamento: "Bolsonaro é racista?". Em seguida a imagem do candidato é retratada ao centro do vídeo com a seguinte fala: "Quero apresentar pra vocês o meu irmão de dez meses.". A imagem se abre e projeta agora a figura do então candidato a deputado federal, Hélio Fernando Barbosa Lopes, o "Hélio Negão", conhecido também como Hélio Bolsonaro, ao lado do candidato a presidente. Com ambos no centro da imagem, Hélio Negão fala: "Demorei um pouquinho, nasci 'tostadinho', mas o nosso coração é verde amarelo.". Bolsonaro retoma a fala e, virando-se para Hélio Negão, o cumprimenta efusivamente com a expressão: "Valeu, negão!". Em seguida, os dois se abraçam com fartos sorrisos em frente à câmera. Hélio negão retoma: "Estamos juntos!". E Bolsonaro conclui: "Valeu, valeu!". O vídeo se encerra novamente com a inscrição: "\#EstouComBolsonaro".

A proximidade da candidatura de Hélio Negão com o presidenciável foi fundamental para blindá-lo de suas próprias manifestações racistas no período eleitoral $^{4}$. Ainda hoje, a presença do atual deputado, Hélio Negão, nas manifestações públicas de Jair Bolsonaro, agora presidente, é recorrente. No período eleitoral, uma reportagem da BBC (CARNEIRO, 2018) identificou o papel essencial de Helio Negão pessoas que troçaram de sua intervenção, afirmou: "Eu fui num quilombo. $O$ afrodescendente mais leve lá pesava sete arrobas. Não fazem nada. Eu acho que nem para procriador ele serve mais. Mais de R\$1 bilhão por ano é gasto com eles $[\ldots . .]^{\prime \prime}$ (DISCURSO..., 2019). 
na campanha presidencial. A presença constante de um negro naquele contexto foi vista pela jornalista como uma estratégia pautada no esforço do candidato se desvencilhar da imagem de candidato racista. Tratava-se de uma vacina contra as críticas provocadas por seu próprio comportamento. Importante notar que, até o dia 14 de setembro, não havia nenhuma imagem que retratasse um negro nas postagens do PSL.

A política presente nas postagens do PSL agiu explorando a diversidade para construir uma unidade em torno dos fundamentos liberais no qual se assenta a campanha e o discurso proposto para a gestão do país. Assim, nem todas as políticas de afirmação identitária e de reconhecimento trazem consigo as mesmas consequências. De fato, uma das críticas mais significativas que se faz às lutas por reconhecimento está no fato de que elas não ultrapassam os limites das lutas por afirmação identitária. Considerando-se a importância deste debate e buscando ampliá-lo, Safatle (2015) propõe que a ação dos grupos espoliados ultrapasse esta dimensão, afirmando transformações sociais revolucionárias ante a mera aceitação de um horizonte normativo no quadro dominado pelas democracias liberais. As posições defendidas no campo da esquerda devem considerar este gesto, visto que a crítica sobre a violação de direitos desses grupos não pode ter um mero efeito compensatório mediante a hegemonia do pensamento neoliberal e do capitalismo. A eleição é um meio privilegiado para se fazer esse debate com a sociedade.

É claro que, no contexto analisado, não se pode falar exatamente em uma política de afirmação estruturada em um programa. Trata-se apenas de uma tentativa de um candidato se proteger do discurso acionado por seus adversários. Porém, no debate crítico sobre o reconhecimento, Fraser (2006) irá destacar que alguns movimentos antidemocráticos podem se servir dessas políticas. Conforme Safatle, enquanto o reconhecimento estiver empenhado em articular laços de reconhecimento e produzir identidades, ele também estará à disposição para justificar práticas antiemancipatórias. O autor entende que a luta de classes não é compreendida como mera expressão contra a injustiça econômica, mas também como uma tentativa de transformação da individualidade para todo processo de reconhecimento social, 
conforme assinala Marx. A afirmação do indivíduo no liberalismo é o que se pretende superar, criando-se condições para afirmação de sujeitos independentes de seus predicados e em condições materiais de realização no mundo.

A opção pelas inserções audiovisuais, em forma de perguntas com respostas e ações do próprio candidato, buscou dar mais credibilidade ao discurso do candidato a presidente. Embora a análise do material produzido tenha sido refletida apenas em uma rede social, nota-se que um número expressivo de mulheres construiu uma resposta diversa que se insurgiu no movimento Ele não contra a candidatura de Bolsonaro. Não apenas as mulheres, mas também homens, entre eles, negros e pobres, a maioria para quem o discurso da esquerda estava voltado, em boa parte, fez opção pela candidatura do PSL.

As categorias acionadas no discurso identitário não impõem limites suficientes para se comportarem discursos conservadores ou mesmo reacionários. Quando se trata de manter intocáveis os pressupostos de uma racionalidade neoliberal, é possível até para o pensamento retrógado acionar para si o direito de reivindicar demandas por representatividade esvaziadas de qualquer projeto emancipatório.

\section{Referências}

CARNEIRO, J. D. Eleições 2018: Deputado federal mais votado no Rio, Hélio Negão desafia quem vê racismo no padrinho Bolsonaro. BBC News, São Paulo, 12 out. 2018. Disponível em: https://bbc.in/2Jl4iy9. Acesso em: 7 nov. 2018.

DARDOT, P.; LAVAL, C. A nova razão do mundo: ensaio sobre a sociedade neoliberal. São Paulo: Boitempo, 2016.

DISCURSO neonazista de Bolsonaro na Hebraica Rio. [S. I.: s. n.], 2017. 1 vídeo (3 min). Publicado pelo canal Ativismo Protestante. Disponível em: https://bit.ly/2Nn1fu1. Acesso em: 26 abr. 2019. 
FERNANDES, V. Marcelo D2 chama deputado eleito de "negão do Bolsonaro" e é acusado de racismo. BHAZ, Belo Horizonte , 31 out. 2018. Disponível em: https://bit.ly/2AK2VWs. Acesso em: 12 fev. 2019.

FRASER, N. Da redistribuição ao reconhecimento? Dilemas da justiça numa era "pós-socialistas". Cadernos de campo, São Paulo, n. 1415, p. 1-328, 2006.

HALL, S. Cultura e representação. Rio de Janeiro: Editora PUC Rio: Apicuri, 2016.

HONNETH, A. Luta por reconhecimento. São Paulo: Editora 34, 2017.

PARTIDO DOS TRABALHADORES. PT - Partido dos Trabalhadores. Brasília, DF, 2018. Instagram: ptbrasil. Disponível em: https://bit.ly/2AL2zi8. Acesso em: 4 fev. 2019.

PARTIDO SOCIAL LIBERAL. PSL - Partido Social Liberal. Brasília, DF, 2018. Instagram: psl_nacional. Disponível em: https://bit.ly/2MkJ05Y. Acesso em: 4 fev. 2019.

PARTIDO SOCIALISMO E LIBERDADE. PSOL - Partido Socialismo e Liberdade. Brasília, DF, 2018. Instagram: psol50. Disponível em: https://bit.ly/2niGO6p. Acesso em: 4 fev. 2019.

SAFATLE, V. Por um conceito "antipredicactivo" de reconhecimento. Lua Nova, São Paulo, n. 94, p. 79-116, 2015.

SAFATLE, V. Só mais um esforço. São Paulo: Três Estrelas, 2017.

submetido em: 31 jul. 2019 | aprovado em: 16 set. 2019 